\title{
Blastic plasmacytoid dendritic cell neoplasm in children: A review of two cases
}

\author{
WENJUN DENG, MINGHUA YANG, FEIMEI KUANG, YINGTING LIU, \\ HUI ZHANG, LIZHI CAO, MIN XIE and LIANGCHUN YANG
}

\author{
Department of Pediatrics, Xiangya Hospital, Central South University, Changsha, Hunan 410008, P.R. China
}

Received October 30, 2016; Accepted August 1, 2017

DOI: $10.3892 / \mathrm{mco} .2017 .1370$

\begin{abstract}
Blastic plasmacytoid dendritic cell neoplasm (BPDCN) is a newly characterized, rare malignant tumor of the skin and hematopoietic system. BPDCN occurs mainly in the elderly, whereas it is rarer among children, and has variable clinical manifestations. Optimal chemotherapeutic regimens for the treatment of BPDCN have not yet been determined and this tumor has a poor prognosis. In this study, two pediatric cases of BPDCN, including a 7-year-old female and a 9-year-old male patient, diagnosed at the Xiangya Hospital of Central South University over the past 2 years, were retrospectively reviewed. Both cases exhibited multiple organ involvement, although the clinical manifestations differed; they were diagnosed with BPDCN based on the clinical manifestations, pathological and immunohistochemical findings, which included positivity for CD4, CD56 and CD123. A high-risk acute lymphocytic leukemia (ALL) chemotherapy regimen was administered to both patients. The patient in the first case achieved a complete remission, but unfortunately her parents refused follow-up treatment and she succumbed to the disease 9 months after the initial diagnosis. The second patient was treated for a total of three courses with a chemotherapy regimen including daunorubicin, cytarabine and etoposide, followed by two courses of the high-risk ALL chemotherapy regimen; unfortunately, a remission was not achieved and the patient was scheduled to receive hematopoietic stem cell transplantation. Thus, not all pediatric BPDCN patients may be able to achieve complete remission following chemotherapy with the high-risk ALL regimen, and other treatment options must be investigated in the future.
\end{abstract}

Correspondence to: Professor Minghua Yang, Department of Pediatrics, Xiangya Hospital, Central South University, 87 Xiangya Road, Kaifu Qu, Changsha, Hunan 410008, P.R. China

E-mail: yamahua123@163.com

Key words: blastic plasmacytoid dendritic cell neoplasm, clinical manifestations, immunohistochemistry, chemotherapy, children

\section{Introduction}

Blastic plasmacytoid dendritic cell neoplasm (BPDCN) is a rare malignant tumor of the skin and hematopoietic system, first described in 1994 as a special type of lymphoma highly expressing CD4/CD56 (1); it was reclassified as a distinct entity, named BPDCN and classified under acute myeloid leukemia (AML) and related precursor neoplasms in the $2008 \mathrm{WHO}$ Classification of Tumors of Haematopoietic and Lymphoid Tissues (2). BPDCN is a highly malignant tumor, clinically characterized by multiple organ involvement, frequently including the skin and bone marrow. Based on the extremely low incidence of BPDCN, which only accounts for $0.44 \%$ of all hematological malignancies (3), a standard and definitive systemic chemotherapy regimen has not yet been established; thus, this disease has a poor prognosis, with a mean survival of 12 months (4). We herein report the cases of two pediatric BPDCN patients who were treated with the chemotherapy regimen for acute lymphocytic leukemia (ALL), in order to determine the optimal treatment protocols and to investigate the differences between adult and pediatric patients.

\section{Case reports}

Case 1. A 7-year-old female patient was hospitalized at Xiangya Hospital of Central South University (Changsha, China) in January, 2015, with complaints of nodular skin lesions of the left leg for 5 months, systemic lymphadenectasis for 2 months and skin ecchymosis for 3 days. The patient reported developing skin nodules in the left leg 5 months prior, without discomfort. A simple surgical resection was performed at another hospital and the results of the pathological examination did not reveal a malignancy; thus, no additional treatment was performed. Two months prior to admission, superficial lymphadenectasis was observed in several regions. Finally, ecchymoses also developed 3 days prior to admission in a number of sites, such as the bilateral periocular region ('raccoon eyes'), conjunctiva, oral mucosa, perineal area and groin. The findings on physical examination were significant, including ecchymoses sized $\sim 4 \mathrm{~cm}$ in the abovementioned regions, and superficial lymphadenectasis with firm, movable and non-tender nodes palpated in the neck, axilla and groin (maximum size, $\sim 3 \times 4 \mathrm{~cm}$ ). There was also hepatosplenomegaly, with the liver palpated $\sim 15 \mathrm{~mm}$ and 
the spleen $\sim 16 \mathrm{~mm}$ under the lower costal margin. The laboratory findings revealed rapidly progressing pancytopenia [white blood cell (WBC) count $15.56 \times 10^{9} / 1$ (normal range, 3.5-9.5x 10\%/1), hemoglobin (HGB) level $124 \mathrm{~g} / 1$ (normal range, $130-175 \mathrm{~g} / \mathrm{l}$ ), and platelet (PLT) count $450 \times 10^{9} / 1$ (normal range, 125-350x10\%/1) on November 29, 2014 vs. WBC $15.3 \times 10^{9} / 1$, HGB $45 \mathrm{~g} / 1$ and PLT $2 \times 10^{9} / 1$ on January 13 , 2015], with serum levels of lactate dehydrogenase elevated to $505 \mathrm{IU} / 1$ (normal range, 120-250 IU/1). Color ultrasonography of the superficial lymph nodes revealed enlarged nodes in the left groin (maximum size, 40x25 mm), whereas color ultrasonography of the abdomen revealed enlarged lymph nodes in the abdominal cavity (maximum size, 28x16 mm) and hepatosplenomegaly, with the liver projecting $\sim 15 \mathrm{~mm}$ and the spleen $\sim 16 \mathrm{~mm}$ under the lower costal margin. A computed tomography (CT) scan of the chest revealed no significant findings. Bone marrow cell morphology examination revealed medullary proliferative activity, with abnormal cells accounting for $\sim 36 \%$, with large cell body mass, scanty cytoplasm, no obvious granules, nucleus partly deflected to one side, elliptical nuclei, peroxidase-, Sudan Black B', acid phosphatase positivity rate $82 \%$, non-specific esterase positivity rate $94 \%$ and sodium fluoride inhibition rate $64 \%$. Most immature cells (96\%) were Periodic acid-Schiff-positive, with dispersed fine particles; thus, acute myeloid leukemia (AML)-M5 was suspected. Flow cytometry analysis of the bone marrow revealed a group of abnormal cells accounting for $19 \%$ of karyocytes, exhibiting weaker expression of CD45 compared with monocytes and slightly more prominent side scatter compared with lymphocytes; these abnormal cells were mainly $\mathrm{CD} 4^{+}, \mathrm{CD}_{3} 3^{+}, \mathrm{CD} 6^{+}$and $\mathrm{CD}_{123^{+}}$, and partly expressed CD117 and CD304; thus, the diagnosis of AML-M5 was considered. Karyotype analysis and leukemia-related fusion gene detection for bone marrow cells also yielded normal results. Biopsy of the nodes in the inguinal region was performed in our hospital after admission, and the results of the pathological analysis were normal; thus, pathological analysis of the skin and nodal tissues that were previously obtained by surgical resection at the other hospital was performed and the possibility of a malignant tumor of lymphohematopoietic cells was considered, with a high likelihood of BPDCN based on the results of immunohistochemistry $\left[\mathrm{CD}^{2} 6^{+++}, \mathrm{CD}^{+}, \mathrm{CD} 3^{-}, \mathrm{CD} 8^{-}, \mathrm{CD} 20^{-}, \mathrm{CD}^{-} \mathrm{a}^{-}\right.$, terminal deoxynucleotidyl transferase (Tdt) ${ }^{-}, \mathrm{Ki}-6740 \%$, $\mathrm{CD}^{+}{ }^{+}$, anaplastic lymphoma kinase (ALK) ${ }^{-}$and myeloperoxidase (MPO)-']. In addition, pathological examination of the skin and nodal tissues that were previously obtained at the other hospital was performed at the Sun Yat-sen University Cancer Center and revealed infiltration of the dermal and subcutaneous tissue by numerous hyperchromatic, small round tumor cells, exhibiting a small amount of cytoplasm, fine chromatin, and inconspicuous nuclear membrane and nucleolus, with a high number of mitotic figures. Immunohistochemistry revealed weak $\mathrm{CD} 56^{+}$, diffuse $\mathrm{CD} 4^{+}$, diffuse $\mathrm{CD}^{2} 3^{+}, \mathrm{Tdt}^{-}, \mathrm{MPO}^{-}$and $\mathrm{Ki}-67$ 40\%; the results of in situ hybridization it for Ebstein-Barr virus-encoded small RNA (EBER) and T-cell receptor (TCR) were negative.

Based on clinical manifestations, pathological and immunohistochemical results, and the positive results for CD4, CD56 and CD123 by bone marrow flow cytometry, the patient was diagnosed with BPDCN and was treated with a high-risk ALL chemotherapy regimen [a total of two courses of treatment with vincristine, daunorubicin, pegaspargase, dexamethasone and prednisone (VDLD regimen) and cyclophosphamide, cytarabine and mercaptopurine (CAM regimen) (Table I), after which the ecchymoses disappeared and the enlarged lymph nodes decreased in size. No abnormal cells were found on morphological examination of the bone marrow, and bone marrow flow cytometry demonstrated that primitive precursor cells accounted for $1.5 \%$ and expressed CD33, CD34, CD123 and CD117. The patient's parents refused follow-up treatment due to financial difficulties and she succumbed to the disease 9 months after the initial diagnosis.

Case 2. A 9-year-old male patient was admitted to the Xiangya Hospital of Central South University (Changsha, China) on January 4, 2016, due to edema of the bilateral maxillofacial region, bilateral testicles and right-sided gingiva, with intermittent fever for $>20$ days that did not improve with antibiotic therapy. In addition, the patient presented with generalized bone pain. On physical examination, there were no visible skin changes. A bean-sized lymph node was palpated in the right submaxillary area, which was firm, movable, and non-tender. There was also bilateral maxillofacial swelling, with bilateral non-tender lumps sized $\sim 2 \times 3 \mathrm{~cm}$. In addition, there was a swelling with a small erosion on the surface of the right-sided lower gingiva, and bilateral testicular edema that was tender on palpation. The findings of routine blood tests were non-significant (WBC 3.6x10 $/ 1$, HGB $122 \mathrm{~g} / 1$, PLT $\left.304 \times 10^{9} / 1\right)$, but there were elevated serum levels of lactate dehydrogenase (505 U/l) and C-reactive protein (100 mg/l). The results of the tests for $\alpha$-fetoprotein, neuron-specific enolase (NSE), ferritin, sex hormone determination and vanillyl mandelic acid were non-significant. Color ultrasonography of the maxillofacial region revealed non-echogenic areas bilaterally (left, 25x8 mm; and right, 24x10 mm). A computed tomography (CT) scan of the maxillofacial region revealed cystic lesions in the bilateral mandibular angles; magnetic resonance imaging (MRI) of the maxillofacial region demonstrated lesions with abnormal signal in the mandible and surrounding muscles bilaterally (right, $\sim 4.4 \times 4.3 \mathrm{~cm}$; and left, $\sim 3.7 \times 3.6 \mathrm{~cm}$ ). A CT scan revealed bilateral enlargement of the testes and epididymis, with rough margin of the bilateral spermatic cord. A whole-body bone scan revealed bone metabolic abnormalities in the bilateral maxilla and mandible, upper right humerus, upper-middle sections of the left humerus, upper right femur and upper left tibia. The findings of the brain MRI were normal; a mediastinal CT scan revealed a soft tissue lesion sized $8.1 \times 3.8 \mathrm{~cm}$ in the anterior mediastinum, and an enhanced CT scan of the abdomen revealed segmental thickening of the rectal and colonic wall to a maximum thickness of $2.4 \mathrm{~cm}$, with multiple retroperitoneal (around the root of mesentery) and pelvic enlarged lymph nodes $(1 \mathrm{~cm})$, and significantly increased size of the bilateral testes. Findings from the bone marrow aspirate were normal at the time of onset, but a second aspirate obtained 20 days later included large abnormal cells, accounting for $31.5 \%$ of karyocytes, considered as AML-M5 cells with round or irregular nuclei, conspicuous chromatin, partially 
visible nucleoli, and abundant cytoplasm with fine granules. The majority of these cells were negative for peroxidase staining and only some were weakly positive. Subsequently, flow cytometry analysis of the bone marrow was performed and revealed a group of abnormal cells accounting for $4 \%$ of the karyocytes, and these cells were positive results for HLD-DR, CD4, CD13, CD15, CD33, CD38, CD56 ${ }^{\text {bri }}$, CD64, CD117 and CD123. Karyotype analysis of the bone marrow cells yielded normal results, but leukemia-related fusion gene detection identified mixed-lineage leukemia/eleven-nineteen-leukemia (MLL/ENL). Histopathological examination of a bone marrow biopsy specimen revealed some abnormal cells of medium to large size, with oval or spindled nuclei, conspicuous chromatin strands and partially visible nucleoli, while the immunohistochemical examination of these abnormal cells revealed that they were $\mathrm{CD}^{-}, \mathrm{CD}^{-}, \mathrm{CD}^{-} 0^{-}$,

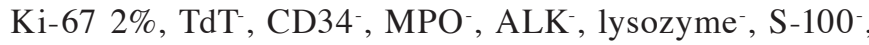
CD117-, Oct-4-, CD5-, chromogranin $\mathrm{A}^{-}$, synaptophysin (Syn) ${ }^{-}, \mathrm{NSE}^{-}, \mathrm{CD}^{+}, \mathrm{CD}^{+}{ }^{+}, \mathrm{CD} 163^{-}, \mathrm{CD}^{+}{ }^{+}$and $\mathrm{CD}^{+} 3^{+}$. Based on these results, a lymphoid hematopoietic malignant tumor was suspected, similar to AML and related tumors. Histopathological examination of a surgical biopsy specimen from the edematous gingiva revealed a neoplasm of suspected myoepithelial origin; the results of the immunohistochemical examination were as follows: $\mathrm{CD}^{-}{ }^{-}$, B-cell lymphoma-6$\mathrm{CD}^{-}{ }^{-}, \mathrm{CD}^{-}{ }^{-} \mathrm{CD}^{-}, \mathrm{Ki}^{-} 67^{+} 20 \%$, paired box 5-, $\mathrm{MPO}^{-}, \mathrm{TdT}^{-}$, multiple myeloma oncogene $1^{-}, \mathrm{CD} 138^{-}, \mathrm{CD} 38^{-}, \mathrm{CD}^{-} 1^{+}$, $\mathrm{CD}^{-} 4^{-}, \alpha-1$ antichymotrypsin ${ }^{+}$, calponin $^{+}$(partly), S-100 ${ }^{+}$ (partly), human melanoma black 45-, P63-, vimentin ${ }^{+}$, leukocyte common antigen-, pan-cytokeratin-, desmin', epithelial membrane antigen $^{ \pm}$, F8 $^{-}$and myogenin ${ }^{-}$. Subsequently, the surgical biopsy specimen from the swelling in the gums was sent to the Sun Yat-sen University Cancer Center for consultation, and the conclusion was that the lesion was considered as BPDCN based on the immunohistochemistry results $\left[\mathrm{CD} 99^{+}, \mathrm{CD} 43^{+}, \mathrm{CD} 56^{+}, \mathrm{CD} 4+, \mathrm{Syn}^{+}\right.$(partly), CD30

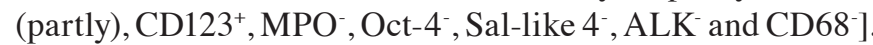
Histopathological examination of a needle biopsy specimen from the mediastinal mass revealed a small-cell malignant neoplasm that was considered to be BPDCN based of the immunohistochemical results (bone marrow, gum and mediastinal mass biopsies) and the bone marrow flow cytometry results. The results of the immunohistochemical examination of tumor cells from the mediastinal mass were as follows: CD3-, CD4 ${ }^{+}, \mathrm{CD}_{56}{ }^{+}, \mathrm{CD}_{4}{ }^{+}, \mathrm{CD}_{117}{ }^{+}$(interspersed), CD68 ${ }^{+}$, $\mathrm{CD}_{163}{ }^{+}, \mathrm{CD} 15-, \mathrm{MPO}-$, lysozyme ${ }^{+}$and Ki-67 15\%.

Based on the clinical manifestations, histopathological findings, immunohistochemistry, and positive results for CD4, CD56 and CD123 by bone marrow flow cytometry, the patient was diagnosed with BPDCN and was treated for a total of three courses with daunorubicin, cytarabine and etoposide (DAE regimen) and two courses of high-risk ALL chemotherapy regimen (VDLD and CAM) (Table I). Unfortunately, the patient did not achieve a remission based on the CT examination of the mediastinum and abdomen. The CT of the maxillofacial region revealed partial remission, as did the whole-body bone scan and color ultrasonography of the testes, whereas the findings of the bone marrow aspiration revealed complete remission. The patient was found to be completely matched with his brother, and the allogeneic hematopoietic stem cell transplantation (allo-HSCT) was performed in May, 2016. Thus far the patient remains alive and relapse-free (date of last follow-up, June 30, 2017).

\section{Discussion}

BPDCN is a rare malignant tumor, and was previously referred to as blastic natural killer (NK) cell lymphoma/leukemia, a granular $\mathrm{CD}^{+} \mathrm{NK}$ cell leukemia, or $\mathrm{CD}^{+} / \mathrm{CD}^{2} 6^{+}$hematodermic neoplasm for a long time of past. Chaperot et al (5) then observed that the BPDCN cells were able to produce $\alpha$-interferon following viral stimulation and differentiate into dendritic cells, while Petrella et al (6) discovered that the tumor cells expressed CD123, similar to the plasmacytoid dendritic cells; thus, it is generally accepted that the origin of BPDCN cells is the plasmacytoid dendritic cell, and the neoplasm was named BPDCN and classified under AML and related precursor neoplasms in the $2008 \mathrm{WHO}$ Classification of Tumors of Hematopoietic and Lymphoid tissue (2). BPDCN is a rare malignant tumor, accounting for $0.44 \%$ of all hematological malignancies (3), and mainly occurs in elderly males, with the median age at onset in the sixth decade of life (7-9) and a male:female incidence rate ratio of 2-7.25:1 (10-13). However, pediatric cases, even in infants and young children, have also been reported $(14,15)$. Clinically, there is nearly always multiple organ involvement, and cutaneous involvement characterized with tumor cells located under the dermis is the main initial presentation of BPDCN in the majority of the cases, although occasionally there is no cutaneous involvement and the disease presents with leukemia symptoms $(16,17)$; in addition, extracutaneous involvement often occurs simultaneously, such as in the lymph nodes, peripheral blood, bone marrow, skeleton, gastrointestinal tract, central nervous system, lung, mediastinum and pancreas (18-21); however, to the best of our knowledge, testicular involvement has not been reported to date. The patient in case 1 exhibited typical clinical manifestations, with initial skin involvement, followed by rapid occurrence of multiple organ involvement (lymph nodes, liver, spleen and bone marrow); as regards the second patient, there was simultaneous occurrence of bilateral maxillofacial involvement, confirmed by histopathological examination of a surgical biopsy specimen, bilateral testicular involvement and mediastinal involvement, confirmed by histopathological examination of a needle biopsy specimen, prior to bone marrow involvement. Thus, the original location of the tumor in this patient could not be determined; however, regardless of the origin, none of these locations have been previously reported to the best of our knowledge, while skin involvement was not observed over the entire course of the disease. Both patients developed leukemia-like symptoms, and both exhibited bone marrow invasion, so that both were misdiagnosed as AML-M5 based on the bone marrow cell morphology, suggesting that the BPDCN cells have a high affinity for the bone marrow, and that BPDCN is not easily distinguished from AML-M5 when the BPDCN cells are located in the bone marrow (Table II).

The diagnosis of BPDCN relies on histopathology and immunohistochemistry. As regards histopathology, the tumor cells comprise a monomorphic population of 
Table I. Chemotherapy regimens.

\begin{tabular}{|c|c|c|}
\hline Protocol & Regimen & Drugs \\
\hline High-risk ALL regimen & VDLD & $\begin{array}{l}\text { Vincristine } 1.5 \mathrm{mg} / \mathrm{m}^{2} \text { on days } 5,12 \text { and } 19 \\
\text { Daunorubicin } 25 \mathrm{mg} / \mathrm{m}^{2} \text { on days } 5 \text { and } 12 \\
\text { Pegaspargase } 2,000 \mathrm{IU} / \mathrm{m}^{2} \text { on days } 6 \text { and } 26 \\
\text { Dexamethasone } 6 \mathrm{mg} / \mathrm{m}^{2} \text { on days } 1-4 \\
\text { Prednisone } 45 \mathrm{mg} / \mathrm{m}^{2} \text { on days } 5-28\end{array}$ \\
\hline & CAM & $\begin{array}{l}\text { Cyclophosphamide } 1 \mathrm{~g} / \mathrm{m}^{2} \text { on day } 1 \\
\text { Cytarabine } 50 \mathrm{mg} / \mathrm{m}^{2} \text { on days } 1-7 \mathrm{Q} 12 \mathrm{~h} \\
\text { Mercaptopurine } 60 \mathrm{mg} / \mathrm{m}^{2} \text { on days } 1-7\end{array}$ \\
\hline AML regimen & DAE & $\begin{array}{l}\text { Daunorubicin } 40 \mathrm{mg} / \mathrm{m}^{2} \text { on days } 1,3 \text { and } 5 \\
\text { Cytarabine } 100 \mathrm{mg} / \mathrm{m}^{2} \text { on days } 1-7 \mathrm{Q} 12 \mathrm{~h} \\
\text { Etoposide } 100 \mathrm{mg} / \mathrm{m}^{2} \text { on days } 1-5\end{array}$ \\
\hline
\end{tabular}

ALL, acute lymphoid leukemia; AML, acute myeloid leukemia.

Table II. Clinical characteristics at diagnosis.

\begin{tabular}{lcccc}
\hline Patients & $\begin{array}{c}\text { Age } \\
\text { (years)/gender }\end{array}$ & Invasion & Bone marrow & Cytogenetics \\
\hline Case 1 & 7/female & Skin, lymph nodes, bone marrow & AML-M5 & $46, X X$ \\
Case 2 & $9 /$ male & Lymph nodes, bone marrow, mediastinum, testes, maxillofacial & AML-M5 & $46, X Y$ ENL/MLL \\
\hline
\end{tabular}

AML, acute myeloid leukemia; ENL, eleven-nineteen-leukemia; MLL, mixed-lineage leukemia.

small-to middle-sized cells, with round or irregular nuclei, conspicuous chromatin, partially visible nucleoli, and scant to moderate amounts of cytoplasm with fine granules (22). As regards immunohistochemistry, the BPDCN cells may be positive for CD4, CD43, CD45RA, CD56, BDCA-2/CD303, BDCA-4/CD304, CD123, T-cell leukemia/lymphoma protein 1 (TCL1), cutaneous lymphocyte antigen, CD68, CD7, CD38, CD99, S-100, TdT and CD31, according to previous reports, and are often negative for lymphoid (CD3, CD19 and CD20) and myeloid (CD117, MPO) markers (6,23-27); EBER, Ig heavy chain rearrangement and TCR rearrangement are also usually negative $(12,24)$. Among the abovementioned results, the positive reaction to CD4, CD56, CD123, TCL1 and CD303 was important for the diagnosis of BPDCN. Julia et al suggested that BPDCN may be diagnosed if 4 of these 5 markers are positive (4). The rate of S-100 positivity is only $25 \%$ in adults but $75 \%$ in pediatric patients, and it may also be used to diagnose this disease and to predict prognosis (14). TdT positivity may be observed in some patients, and a strong positive reaction for TdT ( $>50 \%$ of all tumor cells) predicts a favorable prognosis $(14,28)$. In the present study, immunophenotyping revealed that $\mathrm{CD} 4, \mathrm{CD} 56$ and $\mathrm{CD} 123$ were positive in the two patients and these results were consistent with BPDCN (Table III).

According to previous reports, abnormal cytogenetics was often observed. On karyotype examination, there are common chromosomal abnormalities, including $5 \mathrm{q} 21$ or $5 \mathrm{q} 34$ (72\%), 12p13 (64\%), 13q13-21 (64\%), 6q23 (50\%), 15q (43\%) and complete deletions of chromosome 9 (28\%), but cases with normal karyotype have also been reported (29,30). In the present study, the karyotype examinations of the bone marrow were normal in both patients; however, karyotype examinations of biopsy specimens were not performed. In addition, previous studies reported gene abnormalities, including deletions, such as CDKN1B, CDKN2A-ARF-CDKN2B (31), increased expression, such as HES6, FLT3 and RUNX2 (32), and mutations, such as TET2 and ASXL1 (33); however, to the best of our knowledge, no fusion genes were previously reported. In the present study, leukemia-related fusion gene detection was performed for both patients due to the bone marrow involvement; the results were MLL/ENL-positive (only in case 2) and, to the best of our knowledge, this is the first reported pediatric BPDCN case with a positive result for MLL/ENL. MLL/ENL positivity may be associated with T-ALL or AML-M4/M5 in children, and often predicts a poor outcome; however, its significance for BPDCN patients remains unknown.

There is currently no optimal therapeutic strategy for BPDCN. Chemotherapy, HSCT and targeted therapy have all been used to treat patients with BPDCN. As regards chemotherapy, single agents (such as daunomycin and cytarabine) and combination regimens, such as CVP (cyclophosphamide + vincristine + prednisolone), L-asparaginase + methotrexate, L-asparaginase + methotrexate + dexamethasone all have been used to treat BPDCN, and may achieve complete remission temporarily. However, the disease often relapses within a short time (12,34-36). Hatano et al reported the case of a relapsed BPDCN patient who 
Table III. Pathological and immunophenotypical results of the biopsies.

\begin{tabular}{llcccccc}
\hline Patients & Specimen & CD4 & CD56 & CD123 & S-100 & TdT & Other \\
\hline Case 1 & BM & + & + & + & N & N & CD304/CD117 $^{+}$ \\
& Skin & + & ++ & + & N & - & MPO/EBER/TCR $^{-}$ \\
Case 2 & BM & + & + & + & - & - & $\mathrm{CD}^{+} 117^{+} / \mathrm{MPO}^{-}$ \\
& Gums & + & + & + & + & $\mathrm{MPO}^{-}$ & $\mathrm{MPO}^{-} / \mathrm{CD}^{-} 17^{+}$ \\
& Mediastinum & + & + & $\mathrm{N}$ & $\mathrm{N}$ & $\mathrm{N}$ & \\
\end{tabular}

BM, bone marrow; N, not performed; TdT, terminal deoxynucleotidyl transferase; MPO, myeloperoxidase; EBER, Epstein-Barr virus-encoded small RNAs; TCR, T-cell receptor.

Table IV. Treatment outcomes.

\begin{tabular}{llcl}
\hline Patients & First-line therapy & Response to first-line therapy & Outcome \\
\hline Case 1 & VDLD + CAM & CR & Died after 9 months \\
Case 2 & DAE + VDLD + CAM & NR & Alive at 4 months, planned HSCT \\
\hline
\end{tabular}

CR, complete remission; NR, non-remission; HSCT, hematopoietic stem cell transplantation.

obtained long-term remission following oral administration of low-dose etoposide (37). Jegalian et al treated 29 pediatric BPDCN patients with ALL/Hodgkin lymphoma (HL) regimens and AML regimens, and observed that a better outcome was obtained with ALL/HL regimens compared with AML regimens (14). HSCT is another effective treatment option; Roos-Weil et al reported that all 34 patients who received allo-HSCT after the first complete remission achieved a median survival of 28 months (range, 4-77 months) (38). Suzuki et al treated 6 patients with auto-HSCT, 3 of whom succumbed to disease progression, whereas the remaining 3 patients survived for 11, 22 and 37 months (39); Jegalian et al treated 4 pediatric patients with auto-HSCT, 3 of whom relapsed and had a median survival of 13 months (14). Thus, HSCT may be effective in prolonging survival, but it has not been proven to be curative in BPDCN cases. At present, targeted therapies are under investigation; Frankel et al suggested that SL-401, a new targeted agent, directly acts on the interleukin-3 receptor (CD123) on the surface of BPDCN cells and may exert a curative effect (40). Sapienza et al reported abnormal activity of the nuclear factor (NF)- $\kappa \mathrm{B}$ pathway in the tumor cells of BPDCN and bortezomib, which reduces $N F-\kappa B$ pathway signaling, was tested on tumor cells in vitro, and the results indicated that bortezomib may lead to cell cycle arrest and promote cell apoptosis (41). In the present study, the patient in case 1 achieved complete remission after two courses of treatment with high-risk ALL chemotherapy, but succumbed to the disease 9 months after the initial diagnosis as she did not receive follow-up treatment; a similar chemotherapy regimen was used to treat the patient in case 2 , but the outcome was not as satisfactory. The differences between these two patients leading to different efficacy of the same chemotherapy regimen require further elucidation (Table IV).

In conclusion, the present study was focused on BPDCN in pediatric patients and, despite reporting on only 2 cases, it may provide relevant information that may differ from previous reports. First, as regards clinical manifestations, although both patients exhibited multiple organ involvement, consistently with previous reports, the patient in case 2 had bilateral testicular involvement that, to the best of our knowledge, had not been reported to date, suggesting that the tumor cell may traverse the blood-testis barrier. In addition, the patient in case 2 exhibited maxillofacial, testicular and mediastinal involvement, but the origin could not be determined, although involvement of either site has not been previously reported. This may serve as a reminder that the possibility of BPDCN must be considered when a malignant tumor is encountered in these locations. Second, both patients exhibited bone marrow involvement and were considered as AML-M5 based on bone marrow examination, suggesting that the BPDCN cells are similar to AML-M5 cells on microscopic examination; thus, the possibility of BPDCN must be considered to avoid misdiagnosis when the results of the bone marrow examination indicate AML-M5 with skin involvement, or when these results are not consistent with those of flow cytometry analysis of the bone marrow. Third, the MLL/ENL fusion gene was detected in the patient in case 2. This fusion gene was first identified in pediatric BPDCN patients and is also associated with T-ALL or AML-M4/M5 in children; however, the significance of MLL/ENL positivity in BPDCN patients has not been fully elucidated. Finally, there were several differences between the two patients, as well as an entirely different outcome with the ALL-like-chemotherapy regimen, suggesting that ALL-like-chemotherapy may not be the optimal choice for pediatric BPDCN patients.

Based on the rarity of this disease and its poor prognosis, more studies are required to identify prognostic factors and determine the optimal treatment. The present study may contribute to future research, particularly for BPDCN in children. 


\section{Acknowledgements}

The present study was supported by grants from the National Natural Sciences Foundation of China (nos. 81570154 and 81100359 to M.Y). The authors wish to thank the patients and families who participated in this study. The legal guardians of bothe patients provided written informed consent to the publication of the case details.

\section{References}

1. Adachi M, Maeda K, Takekawa M, Hinoda Y,Imai K, Sugiyama S and Yachi A: High expression of CD56 (N-CAM) in a patient with cutaneous CD14 positive lymphoma. Am J Hematol 47: 278-282, 1994.

2. Swerdlow SH, Campo E, Harris NL, Jaffe ES, Pileri SA, Stein H, Thiele J and Vardiman JW: WHO classification of tumours of haematopoietic and lymphoid tissues 4th edition. Lyon, France, IARC Press, pp191-194, 2008.

3. Bueno C, Almeida J, Lucio P, Marco J, Garcia R, de Pablos JM, Parreira A, Ramos F, Ruiz-Cabello F, Suarez-Vilela D, et al: Incidence and characteristics of CD4(+)/HLA DRhi dendritic cell malignancies. Haematologica 89: 58-69, 2004.

4. Julia F, Dalle S, Duru G, Balme B, Vergier B, Ortonne N, Vignon-Pennamen MD, Costes-Martineau V, Lamant L, Dalac S, et al: Blastic plasmacytoid dendritic cell neoplasms: Clinico-immunohistochemical correlations in a series of 91 patients. Am J Surg Pathol 38: 673-680, 2014.

5. Chaperot L, Bendriss N, Manches O, Gressin R, Maynadie M, Trimoreau F, Orfeuvre H, Corront B, Feuillard J, Sotto JJ, et al: Identification of a leukemic counterpart of the plasmacytoid dendritic cells. Blood 97: 3210-3217, 2001.

6. Petrella T, Comeau MR, Maynadié M, Couillault G, De Muret A, Maliszewski CR, Dalac S, Durlach A and Galibert L: 'Agranular CD4+ CD56+ hematodermicneoplasm' (blastic NK-cell lymphoma) originates from a population of CD56 +precursor cells related to plasmacytoid monocytes. Am J Surg Pathol 26 : 852-862, 2002

7. Facchetti F, Pileri SA, Agostinelli C, Martelli MP, Paulli M, Venditti A, Martelli MF and Falini B: Cytoplasmic nucleophosmin is not detected in blastic plasmacytoid dendritic cell neoplasm. Haematologica 94: 285-288, 2009.

8. Garnache-Ottou F, Feuillard J and Saas P: Plasmacytoid dendritic cell leukaemia/lymphoma: Towards a well defined entity? Br J Haematol 136: 539-548, 2007.

9. Pagano L, Valentini CG, Pulsoni A, Fisogni S, Carluccio P, Mannelli F, Lunghi M, Pica G, Onida F, Cattaneo C, et al: Blastic plasmacytoid dendritic cell neoplasm with leukemic presentation: An Italian multicenter study. Haematologica 98: 239-246, 2013.

10. Julia F, Petrella T, Beylot-Barry M, Bagot M, Lipsker D, Machet L, Joly P, Dereure O, Wetterwald M, d'Incan M, et al: Blastic plasmacytoid dendritic cell neoplasm: Clinical features in 90 patients. Br J Dermatol 169: 579-586, 2013.

11. Dalle S, Beylot-Barry M, Bagot M, Lipsker D, Machet L, Joly P, Dompmartin A, d'Incan M, Maubec E, Grange F, et al: Blastic plasmacytoid dendritic cell neoplasm: Is transplantation the treatment of choice? Br J Dermatol 162: 74-79, 2010.

12. Petrella T, Bagot M, Willemze R, Beylot-Barry M, Vergier B, Delaunay M, Meijer CJ, Courville P, Joly P, Grange F, et al: Blastic NK-cell lymphomas (agranularCD4+CD56+ hematodermic neoplasms): A review. Am JClin Pathol 123: 662-675, 2005.

13. Cota C, Vale E, Viana I, Requena L, Ferrara G, Anemona L, Metze D, Fink-Puches R, Wiesner T and Cerroni L: Cutaneous manifestations of blastic plasmacytoid dendritic cell neoplasm-morphologic and phenotypic variabilityin a series of 33 patients. Am J Surg Pathol 34: 75-87, 2010.

14. Jegalian AG, Buxbaum NP, Facchetti F, Raffeld M, Pittaluga S, Wayne AS and Jaffe ES: Blastic plasmacytoid dendritic cell neoplasm in children: Diagnostic features and clinical implications. Haematologica 95: 1873-1879, 2010.

15. Tokuda K, Eguchi-Ishimae M, Yagi C, Kawabe M, Moritani K, Niiya T, Tauchi H, Ishii E and Eguchi M: CLTC-ALK fusion as a primary event in congenital blastic plasmacytoid dendritic cell neoplasm. Genes Chromosomes Cancer 53: 78-89, 2014.
16. Rauh MJ, Rahman F, Good D, Silverman J, Brennan MK, Dimov N, Liesveld J, Ryan DH, Burack WR and Bennett JM: Blastic plasmacytoid dendritic cell neoplasm with leukemic presentation, lacking cutaneous involvement: Case series and literature review. Leuk Res 36: 81-86, 2012.

17. Suzuki R, Nakamura S, Suzumiya J, Ichimura K, Ichikawa M, Ogata K, Kura Y, Aikawa K, Teshima H, Sako M, et al: Blastic natural killer cell lymphoma/leukemia (CD56-positive blastic tumor): Prognostication and categorization according to anatomic sites of involvement. Cancer 104: 1022-1031, 2005.

18. Starck M, Zewen S, Eigler A and Wendtner CM: Meningeal spread of blastic plasmacytoid dendritic cell neoplasm. Eur J Haematol 93: 175-176, 2014.

19. Maio P, Fernandes C, Afonso A, Sachse F, Cabeçadas J and Cardoso J: Case for diagnosis. An Bras Dermatol 88: 131-133, 2013.

20. Tamura H, Ogata K, Mori S, An E, Tajika K, Sugisaki Y and Dan K: Lymphoblastic lymphoma of natural killer cell origin, presenting as pancreatic tumor. Histopathology 32: 508-511, 1998.

21. Kim Y, Kang MS, Kim CW, Sung R and Ko YH: CD4+ CD56 + lineage negative hematopoietic neoplasm: So called blastic NK cell lymphoma. J Korean Med Sci 20: 319-324, 2005.

22. Shi Y and Wang E: Blastic plasmacytoid dendritic cell neoplasm: A clinicopathologic review. Arch Pathol Lab Med 138: 564-569, 2014.

23. Dzionek A, Fuchs A, Schmidt P, Cremer S, Zysk M, Miltenyi S, Buck DW and Schmitz J: BDCA-2, BDCA-3, and BDCA-4: Three markers for distinct subsets of dendritic cells in human peripheral blood. J Immunol 165: 6037-6046, 2000.

24. Jaye DL, Geigerman CM, Herling M, Eastburn K, Waller EK and Jones D: Expression of the plasmacytoid dendritic cell marker BDCA-2 supports a spectrum of maturation among CD4+CD56+ hematodermic neoplasms. Mod Pathol 19: 1555-1562, 2006

25. Pilichowska ME, Fleming MD, Pinkus JL and Pinkus GS: CD4+/CD56+ hematodermic neoplasm ("blastic natural killer cell lymphoma'): Neoplastic cells express the immature dendritic cell marker BDCA-2 and produce interferon. Am J Clin Pathol 128: 445-453, 2007.

26. Herling M, Teitell MA, Shen RR, Medeiros LJ and Jones D: TCL1 expression in plasmacytoid dendritic cells (DC2s) and the related CD4+CD56+ blastic tumors of skin. Blood 101: 5007-5009, 2003.

27. Petrella T, Meijer CJ, Dalac S, Willemze R, Maynadié M, Machet L, Casasnovas O, Vergier B and Teitell MA: TCL1 and CLA expression in agranular CD4/CD56 hematodermic neoplasms (blastic NK-cell lymphomas) and leukemia cutis. Am J Clin Pathol 122: 307-313, 2004.

28. Leenman EE and Krivolapov IuA: Morphological and immunohistochemical characteristics of blastic NK-cell lymphoma. Arkh Patol 67: 35-37, 2005 (In Russian)

29. Leroux D, Mugneret F, Callanan M, Radford-Weiss I, Dastugue N, Feuillard J, Le Mée F, Plessis G, Talmant P, Gachard N, et al: CD4(+), CD56(+) DC2 acute leukemia is characterized by recurrent clonal chromosomal changes affecting 6 major targets: A study of 21 cases by the Groupe Français de Cytogénétique Hématologique. Blood 99: 4154-4159, 2002.

30. Alayed K, Patel KP, Konoplev S, Singh RR, Routbort MJ, Reddy N, Pemmaraju N, Zhang L, Shaikh AA, Aladily TN, et al: TET2 mutations, myelodysplastic features, and a distinct immunoprofile characterize blastic plasmacytoid dendritic cell neoplasm in the bone marrow. Am J Hematol 88: 1055-1061, 2013.

31. Wiesner T, Obenauf AC, Cota C, Fried I, Speicher MR and Cerroni L: Alterations of the cell-cycle inhibitors p27(KIP1) and p16(INK4a)are frequent in blastic plasmacytoid dendritic cell neoplasms. J Invest Dermatol 130: 1152-1157, 2010.

32. Dijkman R, van Doorn R, Szuhai K, Willemze R, Vermeer MH and Tensen CP: Gene-expression profiling and array-based $\mathrm{CGH}$ classify CD4+CD56+ hematodermic neoplasm and cutaneous myelomonocytic leukemia as distinct disease entities. Blood 109: 1720-1727, 2007.

33. Menezes J, Acquadro F, Wiseman M, Gómez-López G, Salgado RN, Talavera-Casañas JG, Buño I, Cervera JV, Montes-Moreno S, Hernández-Rivas JM, et al: Exome sequencing reveals novel and recurrent mutations with clinical impact in blastic plasmacytoid dendritic cell neoplasm. Leukemia 28: 823-829, 2014.

34. Lopez V, Martí N, Ferrández A, Martin JM and Jordá E: An atypical presentation of a blastic plasmacytoid dendritic cell tumors. J Cutan Pathol 37: e50-e52, 2010. 
35. Fontaine J, Thomas L, Balme B, Ronger-Savle S, Traullé C, Petrella T and Dalle S: HaematodermicCD4+CD56+ neoplasm: Complete remission after methotrexate-asparaginase treatment. Clin Exp Dermatol 34: e43-e45, 2009.

36. Gruson B, Vaida I, Merlusca L, Charbonnier A, Parcelier A, Damaj G, Royer B and Marolleau JP: L-asparaginase with methotrexate and dexamethasone is an effective treatment combination in blastic plasmacytoid dendritic cell neoplasm. $\mathrm{Br}$ J Haematol 163: 543-545, 2013.

37. Hatano Y, Ogata M, Ohishi M, Anan T, Senba K, Yasumatsu T, Katagiri K, Kashima K, Yokoyama S, Kadota JI, et al: Maintenance of long-term remission using oral administration of low-dose etoposide in a patient demonstrating a relapse of blastic natural killer-cell lymphoma. Clin Exp Dermatol 32: 96-97, 2007.

38. Roos-Weil D, Dietrich S, Boumendil A, Polge E, Bron D, Carreras E, Iriondo Atienza A, Arcese W, Beelen DW, Cornelissen JJ, et al: Stem cell transplantation can provide durable disease control in blastic plasmacytoid dendritic cell neoplasm: A retrospective study from the European Group for Blood and Marrow Transplantation. Blood 121: 440-446, 2013.
39. Suzuki R, Suzumiya J, Nakamura S, Kagami Y, Kameoka JI, Sakai C, Mukai H, Takenaka K, Yoshino T, Tsuzuki T, et al: Hematopoietic stem cell transplantation for natural killer-cell lineage neoplasms. Bone Marrow Transplant 37: 425-431, 2006.

40. Frankel AE, Woo JH, Ahn C, Pemmaraju N, Medeiros BC, Carraway HE, Frankfurt O, Forman SJ, Yang XA, Konopleva M, et al: Activity of SL-401, a targetedtherapy directed to interleukin-3 receptor, in blastic plasmacytoid dendritic cell neoplasm patients. Blood 124: 385-392, 2014.

41. Sapienza MR, Fuligni F, Agostinelli C, Tripodo C, Righi S, Laginestra MA, Pileri A Jr, Mancini M, Rossi M, Ricci F, et al: Molecular profiling of blastic plasmacytoid dendritic cell neoplasm reveals a unique pattern and suggests selective sensitivity to NF- $\mathrm{kB}$ pathway inhibition. Leukemia 28: 1606-1616, 2014. 